\section{Organization of Parent Knowledge: Compartmentalization and Integration in Adult Child-Parent Relationships}

Personality and Social

Psychology Bulletin 36(9) 1225-1240

(C) 2010 by the Society for Personality and Social Psychology, Inc

Reprints and permission: http://www. sagepub.com/journalsPermissions.nav DOI: $10.1177 / 0146167210379112$ http://pspb.sagepub.com

@SAGE

\author{
Alicia Limke' and Carolin J. Showers ${ }^{2}$
}

\begin{abstract}
Previous research has demonstrated an association between structure of beliefs about romantic partners and feelings for that partner. Here, the structure of college students' beliefs about their parents was linked to distinct types of ongoing parent-child relationships identified by cluster analysis. An integrative structure of mother knowledge was associated with an evaluatively complex type of relationship (“dealing”), characterized by greater liking and closeness and less cooperation and contact. Positive compartmentalization of mother knowledge was associated with mother relationships that were consistently positive ("denying") across different dimensions. In contrast, the most positive father relationships were reported by daughters with evaluatively integrative father structures. Possible reasons for daughters' tendency to integrate father structures and to compartmentalize mother structures are discussed.
\end{abstract}

\title{
Keywords
}

parent-child relationships, cognitive structure, compartmentalization, integration, relationship closeness

Received August 25, 2009; revision accepted March 28, 2010

Researchers who study adult relationships suggest a variety of strategies that people use to cope with their partners' negative characteristics and behaviors. For example, partners may distance themselves emotionally or physically (Vangelisti \& Young, 2000) or employ cognitively oriented strategies, such as focusing on positive characteristics and ignoring negative ones (Holmes \& Boon, 1990; Johnson \& Rusbult, 1989). They may even transform negative behaviors into positive ones (e.g., reinterpreting criticism as dedication to detail; Murray \& Holmes, 1993).

Of particular interest is the role of cognitive organization in relationship strategies (e.g., Agnew, Van Lange, Rusbult, \& Langston, 1998; Andersen \& Cole, 1990; Baldwin, 1992; Neff \& Karney, 2004). Specifically, Showers and colleagues (Showers \& Kevlyn, 1999; Showers \& Zeigler-Hill, 2004) suggest that strategies for organizing positive and negative beliefs about relationship partners affect how individuals think about partners' negative characteristics and behaviors and predict overall attitudes toward partners and relationship outcomes. In this view, underlying evaluative knowledge structures may either reflect or facilitate other cognitive or behavioral mechanisms. The present study applies the model of evaluative organization of knowledge to parent-child relationships to further our understanding of these cognitiveaffective processes.
Showers (1992) first proposed the model to explain how the organization of positive and negative self-attributes is associated with a person's mood and self-esteem. Depending on the overall content and importance of self-knowledge, both compartmentalization and integration may be adaptive ways to structure positive and negative self-views. Showers and colleagues later applied the model to romantic relationships (Showers \& Kevlyn, 1999; Showers \& Zeigler-Hill, 2004).

One interesting distinction between the models for the evaluative organization of self- versus partner knowledge is the underlying motivation for each. Most individuals are motivated to view themselves positively (or at least to make the best of their bad characteristics), whereas in the case of a romantic partner ending the relationship is often a viable option. In parent-child relationships, motivations may resemble those for the self, in that it is often difficult or undesirable to sever all ties with one's parents. However, the multifaceted nature of parent-child relationships suggests that there are a

\footnotetext{
'University of Central Oklahoma, Edmond, OK, USA

${ }^{2}$ University of Oklahoma, Norman, OK, USA

Corresponding Author:

Alicia Limke, University of Central Oklahoma, Department of Psychology, 100 N. University Drive, Edmond, OK 73034

Email: ALimke@uco.edu
} 
variety of ways of creating emotional or physical distance when parents are perceived as having important negative attributes.

We propose that there may be different types of adult child-parent relationships that correspond to the structure of parent knowledge, especially for parents who are perceived as having important negative attributes. Just as people with evaluatively integrative self-structures seem to minimize the impact of their negative self-beliefs, adult children with evaluatively integrative parent structures may construct relationships that minimize the impact of important negative attributes, without denying them. In contrast, adult children with positively compartmentalized perceptions of their parents (that allow them to ignore or deny negative characteristics) may construct relationships that appear wholly positive despite important negative beliefs. Other relationships (corresponding to negatively compartmentalized knowledge structures) may simply be distanced and low quality, consistent with the extreme negativity of the child's beliefs.

The scope of this project is as follows: (a) to assess college students' beliefs about their parents and the knowledge structures that organize those beliefs, (b) to assess the characteristics of the current adult child-parent relationships and identify distinct types of relationships, especially for parents who are perceived to have important negative attributes, and (c) to test whether the child's organizational structure for parent knowledge predicts the type of relationship reported for each parent.

\section{Evaluative Organization of Knowledge}

\section{Self-Structure}

The model of evaluative organization suggests that depending on the overall content and importance of self-knowledge, different types of organization are adaptive ways of maintaining positive self-evaluations and mood (e.g., Showers, 1992; Showers, Abramson, \& Hogan, 1998). The model identifies two types of self-structure: compartmentalized and integrative. In compartmentalized self-concepts, positive and negative characteristics are separated into distinct aspects of the self, such that each aspect contains primarily positive or primarily negative beliefs about the self. For example, a compartmentalized individual may describe his "student" self-aspect as comfortable, confident, and intelligent but his "employee" self-aspect as lazy, inferior, and irritable. In contrast to compartmentalized self-concepts, integrative self-concepts are characterized by a mixture of positive and negative self-beliefs in each aspect. For example, an integrative individual may describe herself as a student as successful and capable but also weary and tense.
Because these different types of organization of selfknowledge are believed to affect the accessibility of positive and negative self-beliefs, evaluative organization may moderate the impact of specific beliefs on self-esteem and mood (Showers, 1992). Specifically, the basic model predicts that when positive self-aspects are important, compartmentalized structures (i.e., segregating positive and negative self-traits into separate self-aspect categories) will be associated with the most positive outcomes, such as lower depression and higher self-esteem. In this way, compartmentalization allows individuals to "sweep negative characteristics under the rug," allowing them to maintain positive self-views. In contrast, when negative self-aspects are important, integrative structures (i.e., allowing a mixture of positive and negative traits in each self-aspect category) will be associated with the most positive outcomes. By mixing negative traits with positive ones, individuals cushion the effect of their salient negative traits. For example, when adult children think of their negative parents as unreliable, they may also remember that their parents are often fun and entertaining, which may allow them to maintain relatively positive views of their negative parents.

\section{Partner Structure}

The model of evaluative organization has also been applied to the organization of knowledge about a romantic partner. When individuals described their partners with many positive attributes, compartmentalized structures were associated with relatively positive current feelings for the partner (Showers \& Kevlyn, 1999). Interestingly, these positive feelings may have been "rose colored" given that these relationships were more likely to have ended 1 year later (Showers \& Zeigler-Hill, 2004). Conversely, individuals who described partners as having many flaws reported relatively positive current feelings for the partner if partner structures were integrated, but these relationships also were especially likely to have ended within 1 year. Thus, among individuals with relatively positive partners, modest feelings associated with integration may be realistic and associated with long-lasting relationships; however, when there are substantial negative partner attributes, integrative structures make the best of a bad situation in the short term, but they may also require high effort and may not sustain the relationship over the long term.

\section{Adult Child-Parent Relationships}

\section{Relationship Characteristics}

Traditionally, relationships between adult children and their parents were viewed merely as continuations of the formative parent-child relations established in infancy and childhood (e.g., Bowlby, 1969; Mahler, 1975). However, recent perspectives suggest that parent-child relationships change with 
major life transitions, such as adult children leaving home for the first time (Greene \& Boxer, 1986). There is considerable ambiguity, however, as to what defines the quality of relationships between adult children and their parents. Belsky, Jaffee, Hsieh, and Silva (2001) adopted a model of family solidarity in which interrelated relationship dimensions shape the family across adulthood. They proposed two main components of solidarity, affectional solidarity (feelings of love and appreciation, dependence, good communication and understanding, lack of conflict) and associational solidarity (degree of contact between the parent and child and amount of reciprocal assistance in the relationship), highlighting the characteristics of closeness, contact, and conflict in relationships.

Aquilino (1997) emphasized mutuality in the relationship, proposing four main components: emotional closeness (the extent to which the relationship involves humor and affection), shared activities (the frequency with which the pair shares activities, meals, and other enjoyable times), support from the child (the likelihood of relying on the child for emotional support or advice), and control conflict (the extent to which the parent's desire for control over the child causes problems in the relationship). Thus, Aquilino suggested that attitudes toward parents, closeness, and conflict are important predictors of the quality of parent-child relationships.

Others have emphasized affectional bonds and independence in the relationship. Frank, Avery, and Laman (1988) proposed three dimensions, connectedness (empathy, communication, and emotional closeness), competence (ability to make decisions independent of their parents), and emotional autonomy (respect, personal control, and self-assertion in the relationship), suggesting that emotional closeness as well as relationship control predict relationship quality. Other important dimensions include adult children's attributions for parents' behaviors (Fincham, Beach, Arias, \& Brody, 1998) and sense of interpersonal control (Cook, 1993).

To summarize, this literature highlights both intrapersonal (child's perceptions of parents) and interpersonal (characteristics of the relationship) dimensions. Specifically, indices of intrapersonal dimensions include attitudes toward parents (e.g., how positively or negatively they view them) and attributions for parents' negative behaviors. Indices of interpersonal processes include measures of closeness and conflict. Other important interpersonal features include amount of contact and shared activities, feelings of competence and autonomy, social support given and received, and perceived control over relationship outcomes.

\section{Relationship Types}

Some research characterizes the relationship as a whole rather than specific dimensions. In lower quality relationships, such as those associated with family dysfunction or divorce, type of relationships may correspond to strategy for managing problematic aspects (Riggio, 2004). In particular, relationships with negative parents may be characterized by enmeshment between parents and adult children (in which there are weak boundaries between parent and child, such that the child becomes responsible for parents' emotional wellbeing), disengagement (in which boundaries are overly rigid), or a continuum between the two (Jacobvitz \& Bush, 1996; Mackensen \& Cottone, 1992; Watt, 2002). Consistent with the latter view, we suggest that some adult children with negative parents have what we call "realistic" relationships, in which boundaries are managed reasonably well. Although these children might not wish to end their relationships with their parents, they may respond to their parents' negative characteristics and behaviors. For example, they may limit contact with their parents and seek material independence, even while maintaining positive feelings and relative closeness.

\section{Parent Structure and Relationship Types}

The present study considers whether these qualities of adult child-parent relationships may be linked to strategies of evaluative organization. Because compartmentalization and integration were originally conceptualized as alternative strategies for how an individual handles salient negative attributes or beliefs, we focus here on how college students manage problematic beliefs and troubled relationships; that is, relationships with parents whom the college-age child perceives as having important negative attributes. Compartmentalization (in which positive and negative traits are segregated into separate parent aspect categories) may allow adult children to focus on either parents' positive characteristics or negative characteristics by allowing them to devalue or avoid traits of the opposite valence. Specifically, positive compartmentalization (in which positive and negative traits are segregated into separate parent aspect categories and the positive ones are rated as more important) may allow adult children to isolate negative beliefs about their parents to specific situations or contexts (e.g., "my dad when he's drinking"). This structure would allow children to devalue these aspects of their parents (e.g., by saying that those specific situations are not important to their relationships with them). Positive compartmentalized structures may even represent a form of denial if they allow children to ignore or avoid negative attributes that are ultimately destructive to relationships with parents. Adult children may feel and act toward parents as if negative characteristics of the parents are trivial or do not exist. Thus, the relationship can become unrealistically close. Given the present focus on the process by which negative attributes are devalued or ignored, we label these relationships as "denying."

Similarly, because adult children are focused solely on negative traits and behaviors, negative compartmentalization (segregating positive and negative traits into separate 
parent aspect categories and rating the negative ones as more important) is likely to be associated with a distant relationship. Negative compartmentalization may accentuate parents' negative characteristics, encouraging disengagement and low contact to avoid conflict. We label this type of relationship, in which there is both physical and emotional distance, as "distancing."

In contrast, integration (allowing a mixture of positive and negative traits in each category) may help adult children cope with parents' negative characteristics by allowing them to focus on positive characteristics and behaviors as well. Integrative styles may be associated with realistic relationships. Although these children are aware of their parents' problems, they are also reminded of their parents' positive attributes, which might provide them with reasons for preserving the relationship. For example, a child might report that his or her father is controlling and aggressive but also remember that he is reliable and strong. By repeatedly linking parents' negative attributes to something more positive, adult children may be able to maintain positive overall impressions of their parents, along with feelings of warmth and closeness. However, parents' salient negative attributes could cause a child to limit physical contact or avoid asking for help or offering to provide help. We label this mixed type of relationship as "dealing."

The present study examines the structure of parent knowledge in a sample of college-age children and its association with specific qualities of the ongoing parent-child relationship. The conceptual hypothesis is that knowledge structures correspond to distinct relationship types, motivated by underlying strategies for managing perceived negative attributes and beliefs.

\section{Current Study}

College students performed two card sorting tasks to generate descriptions of their parents. They also completed questionnaires assessing various dimensions of parent-child relationships, including attitudes toward each parent. The analysis has four steps:

Step I: Current feelings. Preliminary analyses test the replication of the basic model of evaluative organization in the domain of parent knowledge. Among children whose perceptions of parents are relatively positive, compartmentalized structures should be associated with greater liking or loving than should integrative structures; among children whose perceptions of parents are relatively negative, integrative structures should be associated with greater liking or loving than should compartmentalized structures.

Step 2: Parent-child relationship types. Factor analysis is used to combine the child's reports of relationship characteristics and attitudes toward parents into fundamental dimensions of parent-child relationships. Then, cluster analyses identify groups of individuals whose parent-child relationships are similar across relationship dimensions. We predict that among adult children who perceive their parents as having at least some important negative attributes, we will find relationship clusters corresponding to the hypothesized relationship types labeled "denying," "dealing," and "distancing."

Step 3: Linking parent structure to relationship type. Regression analyses examine whether content and structure of parent knowledge predict the fit of the parent-child relationship to the different relationship types (for those who perceive their parents as having at least some important negative attributes). We predict that a positively compartmentalized parent structure will be associated with good fit to the denying type of relationship. In contrast, integrative parent structures will be associated with good fit to the dealing type of relationship. Adult children with a negatively compartmentalized parent structure will have the most negative relationships (distancing).

Step 4: Moderating effects of child gender. Because female and male adult children might respond differently to negative attributes of mothers and fathers, child gender is examined as a possible moderator of the links between parent structure and relationship type.

\section{Method}

\section{Participants}

Participants were 230 undergraduates (171 females) enrolled in introductory psychology at the University of Oklahoma who participated in exchange for research exposure credits. The average age of participants was 19.48 years $(S D=2.73)$. Participants were $80 \%$ White, $4 \%$ Black, $8 \%$ Native American, $4 \%$ Asian, 3\% Hispanic, and 1\% Other race/ethnicity. Mothers' education was $19 \%$ high school education or less, $10 \%$ some college or vocational training, and $71 \%$ college or graduate degree. Similarly, fathers' education was $15 \%$ high school education or less, $13 \%$ some college or vocational training, and $72 \%$ college or graduate degree. On average, participants reported living with their mothers for 18.06 years $(S D=2.58)$ and fathers for 16.37 years $(S D=4.81)$.

The final sample was restricted to those participants who described two living biological (or adoptive) parents. The rationale was that the motivation to maintain a functional relationship with a parent figure would be substantially different if that person were deceased or were a nonadoptive stepparent. Of the 230 individuals who completed the study, 26 were excluded from analyses because of family structure (15 indicated nonbiological fathers, 4 indicated both parent figures were nonbiological relatives, 3 referred to nonbiological mothers, 3 referred to deceased fathers, and 1 referred to a deceased mother). Those who were excluded did not differ from the remaining sample on gender, age, racial/ethnic minority status, or level of mother's education. They did differ with respect to father's education, $t(228)=1.94, p<.055$, and stability of household structure, $t^{\prime}(28.70)=2.06, p<.05$. 
Table I. Actual Card Sorts Illustrating Compartmentalized and Integrative Organization of Parent Knowledge

\begin{tabular}{|c|c|c|c|c|c|}
\hline \multicolumn{6}{|c|}{ Panel A: Compartmentalized organization } \\
\hline \multicolumn{2}{|c|}{ At work } & $\begin{array}{l}\text { Before the divorce } \\
\text { (my age: } 0-7)\end{array}$ & $\begin{array}{l}\text { After the divorce } \\
\text { (my age: } 7-17)\end{array}$ & \multicolumn{2}{|c|}{ After the divorce (my age: I7-present) } \\
\hline Capable & Satisfied & -Cold & -Insecure & Happy & Tolerant \\
\hline Intelligent & Confident & -Controlling & -Uncomfortable & Lovable & Encouraging \\
\hline Independent & Admirable & -Self-centered & -lsolated & Comfortable & Forgiving \\
\hline Organized & Hardworking & -Aggressive & -Inconsiderate & Nurturing & Flexible \\
\hline Energetic & Successful & -Irritable & -Tense & Friendly & Mature \\
\hline & & -Disagreeing & -Irritable & Interested & Giving \\
\hline & & & -Controlling & Reliable & Needed \\
\hline & & & -Not the real "him" & Fun and entertaining & \\
\hline \multicolumn{6}{|c|}{ Panel B: Integrative organization } \\
\hline Parent & Professional & Friend & Family & Work & Husband \\
\hline Forgiving & Satisfied & Independent & Giving & Intelligent & Comfortable \\
\hline Giving & -Tense & Forgiving & -Sad and blue & -Weary & Giving \\
\hline -Irritable & Admirable & Giving & -Weary & Giving & -Weary \\
\hline Successful & Intelligent & Friendly & -Irritable & Hardworking & Admirable \\
\hline Admirable & Giving & -lsolated & Admirable & Tolerant & Lovable \\
\hline Lovable & Capable & Lovable & -Tense & Capable & Nurturing \\
\hline Comfortable & -Weary & -Tense & Tolerant & -Tense & -Submissive \\
\hline -Neglectful & Hardworking & & -Uncomfortable & Interested & -Tense \\
\hline Tolerant & & & -Aggressive & Admirable & Tolerant \\
\hline Flexible & & & & & \\
\hline
\end{tabular}

Note:A minus sign indicates negative attributes. These father card sorts, including the aspect labels, were generated by two participants in this study. Panel $\mathrm{A}$ : compartmentalization $=1.00$, proportion of negative attributes $=.36$, love-like $=-.07$; Panel B: compartmentalization $=.35$, proportion of negative attributes $=.32$, love-like $=-.42$.

\section{Materials}

Parent structure. A card sorting task measured the content and structure of beliefs about the parent. This task has been used to assess the structure of knowledge about the self (Showers, 1992; cf. Linville, 1987; Zajonc, 1960) and romantic partners (Showers \& Kevlyn, 1999). Participants were provided with a deck of 60 cards, each containing a trait that could describe a parent. The deck contained 30 positive attributes (e.g., outgoing, nurturing) and 30 negative attributes (e.g., irritable, irresponsible). ${ }^{1}$ Participants were told, "Your task is to think of the different aspects of your mother/father or your mother's/father's life, and then form groups of traits that go together, where each group of traits describes an aspect of your mother/father or your mother's/father's life" (for complete instructions, see Showers \& Kevlyn, 1999). Participants could form as many or as few groups as they desired and use as many or as few traits in each group as they wished. They did not have to use all of the cards. Following the card sort, participants rated the positivity, negativity, and importance of each group generated on 7-point Likert-type scales.

Evaluative organization (phi). The measure of evaluative organization (compartmentalization) is a phi coefficient based on a chi-square statistic (cf. Cramer, 1945/1946, p. 443) that compares the frequencies of positive and negative traits in each group to what would be expected by chance given the proportion of negative items in the card sort overall (i.e., the chance values for organizing positive and negative attributes in self-aspects without regard for valence of the attributes). Phi can range from 0 (perfect integration; positive and negative attributes are evenly distributed across all parent aspects) to 1 (perfect compartmentalization; each parent aspect contains either positive or negative traits). Phi is only computed if two or more negative attributes are included in the card sort. The sample card sorts shown in Table 1 illustrate high compartmentalization (Panel A: $\Phi=1.00$ ) and low compartmentalization (Panel B: $\Phi=.35$ ) of parent knowledge.

Differential importance $(\mathrm{DI})$. DI is a measure of the relative importance of each parent aspect (cf. Pelham \& Swann, 1989). It is computed as the correlation between individuals' ratings of the importance of each aspect and the difference between positivity and negativity ratings for each aspect. DI scores can range from -1 to 1 , with positive scores indicating that positive aspects are considered more important than negative ones and negative scores indicating that negative aspects are considered more important than positive ones.

Proportion of negative attributes (neg). The proportion of negative attributes is a measure of parent knowledge that is calculated as the number of negative attributes used in the card sort divided by the total number of items. 
Intrapersonal relationship variables. Rubin's (1970) Loving and Liking scales for romantic relationships were adapted to assess attitudes toward the parent (e.g., Loving: "I would forgive my mother for practically anything"; Liking: "I think that my mother is one of those people who quickly win respect"). The Adult Attachment Scale (AAS; Cicirelli, 1995) also provided an index of positive feelings for the parent (e.g., "Being with my mother makes me feel very happy" and "I feel lonely when I don't see my mother often").

An adapted form of the Relationship Attribution Scale (RAS; Fincham \& Bradbury, 1992) assessed attributions for parents' negative behaviors. Participants read four statements of negative behaviors (e.g., "Your mother criticizes something you say"). The locus, stability, and globality dimensions were reversed and combined to provide a measure of positive attributions for parental behaviors.

Interpersonal relationship variables. These variables include multiple indices of closeness and conflict as well as individual measures identified by the literature review. Measures of closeness include the Miller Social Intimacy Scale (Miller \& Lefcourt, 1982), with subscales for Frequency (e.g., "How often do you confide very personal information to her?") and Intensity (e.g., "How important is it to you to listen to her personal disclosures?"), and the Inclusion of Other in Self Scale (Aron, Aron, \& Smollan, 1992). The measure of conflict came from the Quality of Relationships Inventory (Pierce, Sarason, \& Sarason, 1991), which has subscales for Social Support (e.g., "To what extent can you count on your mother to listen to you when you are angry at someone else?"), Depth (e.g., "How significant is this relationship in your life?"), and Conflict (e.g., "How angry does your mother make you feel?").

Items revised by Belsky and colleagues (2001) provided measures of perceived interdependence (amount of assistance adult children gave to and received from their parents) as well as current levels of contact (and desired levels of future contact). The Strength scale of the Relationship Closeness Inventory (Berscheid, Snyder, \& Omoto, 1989; e.g., "My mother influences the basic values that I hold") provided a measure of parental influence, and the Interpersonal Sense of Control Scale (Cook, 1993) assessed adult children's feelings of relative control over their relationships with their parents. Following the recommendation of W. L. Cook (personal communication, April 5, 2005), average scores for the Acquiescence subscale (indexing parental control) were subtracted from average scores for the Effectance subscale (indexing personal control) to create a measure of relative control of the relationship.

Parental attribute ratings. For a general assessment of parents' positive and negative characteristics, participants rated the number of positive and negative attributes their mothers and fathers possessed compared to other college students' parents on scales ranging from 1 (lowest 5\%) to 10 (top 5\%). Participants made four ratings: father's positive characteristics, father's negative characteristics, mother's positive characteristics, and mother's negative characteristics.

\section{Procedure}

Participants completed two laboratory sessions (a mother session and a father session) scheduled 1 week apart. The order of the sessions was counterbalanced across participants. There were 2 to 12 participants in each session. For the mother session, participants were told,

In today's session, we'll be focusing on your mother or a person who is a mother figure in your life. For most people, this will be your biological mother, as long as you know her well enough to answer questions about her and your relationship with her.

Additional instructions were given to select a mother figure if no biological mother was available. Participants then answered demographic questions about their mothers, performed the card sorting task to describe their mothers, and completed the intrapersonal and interpersonal questionnaires for their mother relationship. In the father sessions, the same tasks were completed for participants' father relationship.

\section{Results and Discussion}

\section{Step I: Current Feelings}

This section summarizes analyses that replicate the basic model of compartmentalization in the domain of parent-child relationships but do not represent the main contribution of this article. The report of these findings is intentionally brief. The model predicts an interaction of compartmentalization (phi) and DI. The analyses are multiple regressions for mothers and fathers, respectively, in which the Phi $\times$ DI interaction is tested, controlling for the proportion of negative attributes in the card sort. Consistent with previous studies of compartmentalization, these analyses were performed for the samples of 172 mothers and 175 fathers whose card sort descriptions contained at least two negative attributes. Following the approach of Showers and Kevlyn (1999), the criterion variable was love-like, a composite measure of the Loving and Liking scales (Rubin, 1970).

Table 2 presents the intercorrelations of the variables used in the regressions for mothers (below the diagonal) and fathers (above the diagonal), respectively. Note that the correlations between mothers and fathers (shown on the diagonal) are fairly low, even for the full sample, for example, liking, $r(N=204)=.16, p<.05$.

Turning to the regressions, both analyses (mother lovelike and father love-like) obtained significant main effects for DI and neg. More importantly, both regressions obtained significant Phi $\times$ DI interactions, $\beta \mathrm{s}>.14, p s<.05$, replicating 
Table 2. Intercorrelations for Measures of Compartmentalization (Phi), Differential Importance (DI), Proportion of Negative Attributes (Neg), Loving and Liking for Mothers (Below Diagonal), for Fathers (Above Diagonal), and Between Mothers and Fathers (on Diagonal)

\begin{tabular}{|c|c|c|c|c|c|c|}
\hline Variable & I & 2 & 3 & 4 & 5 & 6 \\
\hline I.Phi & $.42 * *$ & $.25^{* * *}$ & $.46 * * *$ & -.05 & $-.18 *$ & -.12 \\
\hline 2. DI & .05 & $.26 * *$ & -.15 & $.30 * * *$ & $.21^{* *}$ & $.27^{* * * *}$ \\
\hline 3. Neg & $.54 * *$ & $-.26 * *$ & $.22 * *$ & $-.45 * * *$ & $-.56 * * *$ & $-.54 * * * *$ \\
\hline 4. Loving & $-.20 * *$ & $.52 * * *$ & $-.53 * * *$ & $.21 * *$ & $.77 * * *$ & $.94 * * *$ \\
\hline 5. Liking & $-.23 * *$ & $.40 * * *$ & $-.65 * * *$ & $.80 * * *$ & $.16^{*}$ & $.94 * * *$ \\
\hline 6. Love-like & -.23 ** & $.48 * * *$ & $-.62 * * *$ & $.95 * * *$ & $.95 * * *$ & $.18 *$ \\
\hline
\end{tabular}

Note:Values below the diagonal are based on college students' descriptions of their mothers $(N=172)$. Values above the diagonal are based on college students' descriptions of their fathers $(N=175)$. These correlations are for cases that had valid values of phi (i.e., at least two negative attributes in the child's card sort description of mother or father).Values on the diagonal represent correlations of mother descriptions with father descriptions (phi $N=155 ; \mathrm{DI} N=182$; all other variables $N=204$ ). $*_{p}<.05$. **p $<.01 . * * * p<.001$.

the results predicted by the basic model and previously demonstrated for both self- and partner structure (Showers \& Kevlyn, 1999; Showers \& Kling, 1996). Among adult children whose perceptions of their parents are basically positive (high DI), compartmentalization is associated with greater liking or loving than is integrative organization. Previous research has also found a negative association between compartmentalization and liking or loving for the low DI group, which is not significant here. One possible explanation is that attachment processes in parent-child relationships prevent adult children's attitudes toward parents from becoming too negative even when the child's parent structures are negatively compartmentalized.

\section{Step 2: Parent-Child Relationship Types}

Factor analyses. Because of the potential overlap among multiple measures of interpersonal variables, these measures were factor analyzed (separately for mothers and fathers) using principle axis factoring with direct oblimin rotation. The full samples of 204 mothers and 204 fathers were used. Eleven variables were entered into the factor analysis: given assistance, received assistance, strength, current contact, ideal contact, social support, (lack of) conflict, depth, intimacy, inclusion of other, and relative control. The factor analyses for both mothers and fathers generated three factors with eigenvalues greater than 1 . The fourth factor had eigenvalues close to 1 (.91 for mothers and .78 for fathers) and contained only a single variable, relative control. Hence, a four-factor solution accommodated all variables. Table 3 presents the results of the analysis for mothers, constrained to four factors. (The results for fathers are extremely similar.) Variables were assigned to factors based on their highest loadings. The first factor was labeled Closeness (eigenvalues were 4.59 for mothers and 5.54 for fathers) and included measures of emotional intimacy, social support, and lack of conflict in the relationship. The second factor was labeled Contact (eigenvalues were 1.51 for mothers and 1.05 for fathers) and included measures of both current and ideal amounts of contact with the parent. The third factor was labeled Cooperation (eigenvalues were 1.12 for mothers and 1.37 for fathers) and included measures of assistance received and given as well as the amount of influence the parent has over the child's decisions and behaviors. The fourth factor was labeled Control (eigenvalues were 0.91 for mothers and 0.78 for fathers) and included the measure of relative control over the relationship. To create factor scores for these interpersonal relationship processes, individual scale scores were standardized and then averaged for each factor.

Dimension scores were also created for two sets of intrapersonal variables: attitudes and attributions. For attitudes, the total score from the AAS was standardized and averaged with the previously computed love-like variable for each parent $\left(r_{\text {mothers }}=.85, r_{\text {fathers }}=.85\right)$. The RAS provided the measure of attributions.

Cluster analyses. Because this study focuses on how parentchild relationships accommodate negative parent characteristics, participants' ratings were used to identify parents who had at least some important negative attributes. Specifically, participants rating their parent in the lowest $5 \%$ of all parents in the number of negative characteristics they possess (i.e., the purely positive parents) were excluded from these analyses. This criterion excluded $25 \%$ of mothers and $17 \%$ of fathers, resulting in $N_{\text {mothers }}=129, N_{\text {fathers }}=145$.

Distinct relationship types were then identified for mothers and fathers using LatentGold 3.0 to compute latent class model cluster analyses with an expectation maximization (EM) algorithm (cf. McLachlan \& Krishnan, 1997). Unlike other forms of cluster analysis that assign observations to clusters to minimize within-group differences and maximize between-group differences (and thus, create clusters that are maximally different from each other on each characteristic), the EM algorithm seeks to create the best overall fit of the data to the proposed number of clusters. It computes probabilities of assignment to each cluster (i.e., it provides information concerning each child's potential "fit" to each relationship type) and also assigns each case to the cluster with the best fit. Factor scores for each of the intrapersonal and interpersonal relationship dimensions (attitude, attribution, closeness, contact, cooperation, and control) were entered into the cluster analyses. Based on the number of expected relationship types (dealing, denying, and distancing), solutions were constrained to three clusters for both mothers and fathers. Overall, these three-cluster solutions represented the data well: for mothers, Wald $\chi^{2}=7.39, p<.05$ (classification errors $=.05$ ); for fathers, Wald $\chi^{2}=36.24, p<.001$ (classification errors $=.03$ ). 
Table 3. Mothers: Factor Loadings for Mother Interpersonal Variables

\begin{tabular}{lcccr}
\hline Scale & Factor I: Cooperation & Factor 2: Contact & Factor 3: Closeness & Factor 4: Control \\
\hline Support (QRI) &. $\mathbf{8 9}$ & .37 & .44 & -.01 \\
Intimacy (MSIS) & .89 & .39 & .46 & .06 \\
Depth (QRI) &. $\mathbf{8 1}$ & .47 & .60 & -.15 \\
Conflict (QRI) & .59 & .22 & .13 & .24 \\
Inclusion of other (IOS) & .53 & .40 & .47 & -.04 \\
Ideal contact (AS) & .45 & .90 & .41 & -.19 \\
Current contact (AS) & .44 & .80 & .32 & .04 \\
Received assistance (AS) & .50 & .51 & .87 & -.14 \\
Given assistance (AS) & .29 & .34 & .59 & -.07 \\
Strength (RCI) & .23 & .29 & .55 & -.46 \\
Relative control (ISOC) & -.07 & -.01 & -.09 & .5
\end{tabular}

Note: $N=204$. QRI = Quality of Relationships Inventory; MSIS = Miller Social Intimacy Scale; IOS = Inclusion of Other in Self Scale; AS = Associational Solidarity; $\mathrm{RCI}=$ Relationship Closeness Inventory; ISOC = Interpersonal Sense of Control Scale.

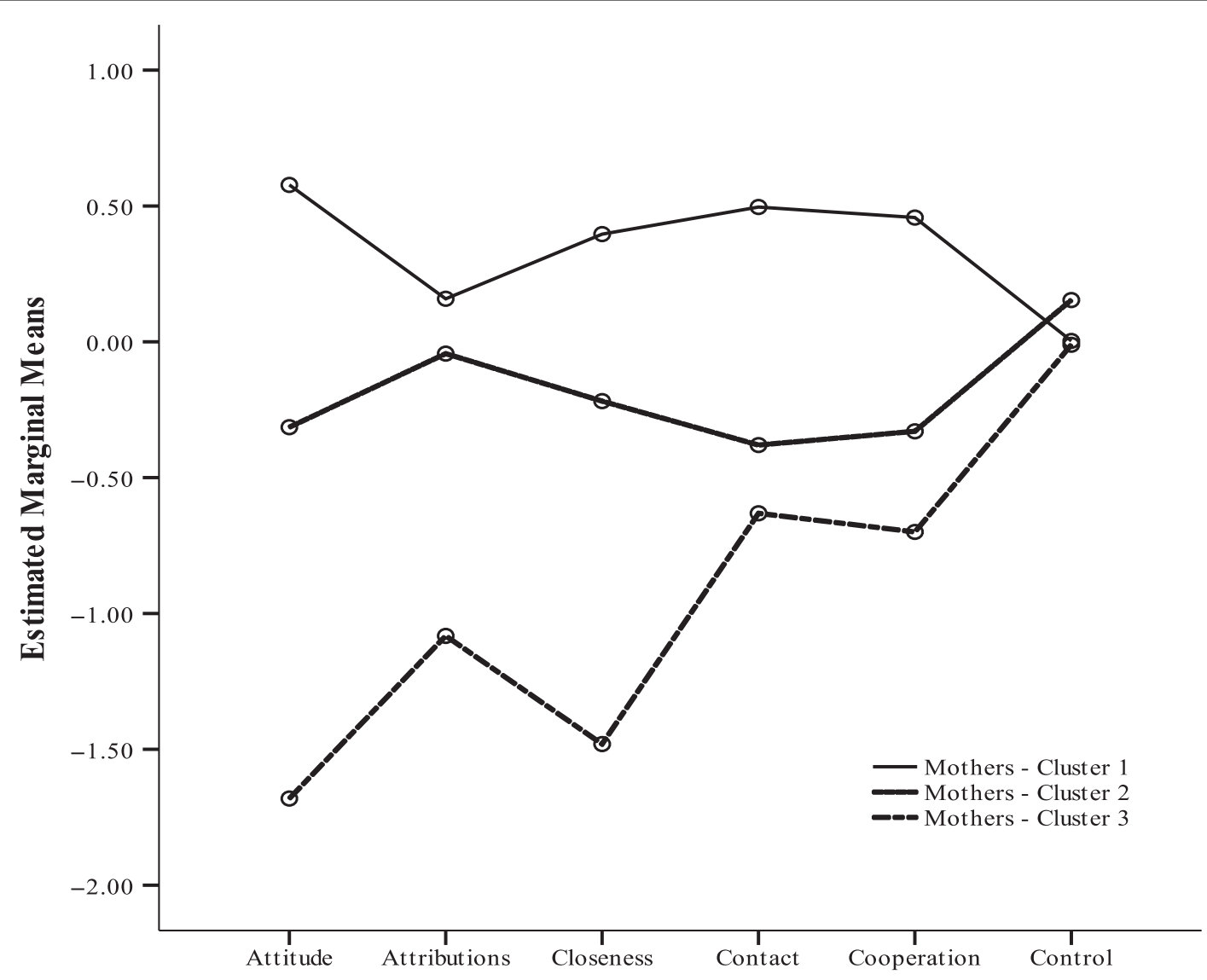

Figure I. Mothers: Estimated marginal means for each cluster on intrapersonal and interpersonal relationship dimensions

Figure 1 (mothers) and Figure 2 (fathers) show the scaled values on each dimension for each cluster. These values were compared across clusters using a multivariate analysis of variance (MANOVA) followed by Games-Howell multiple comparison procedures for unequal variances (see Table 4).
Our interpretations rely on these tests as indicators of how the clusters compare on each dimension.

For mothers, Cluster 1 ( $n=51)$ was characterized by very positive scores on most dimensions, namely, attitude, closeness, contact, and cooperation. However, attributions can only 


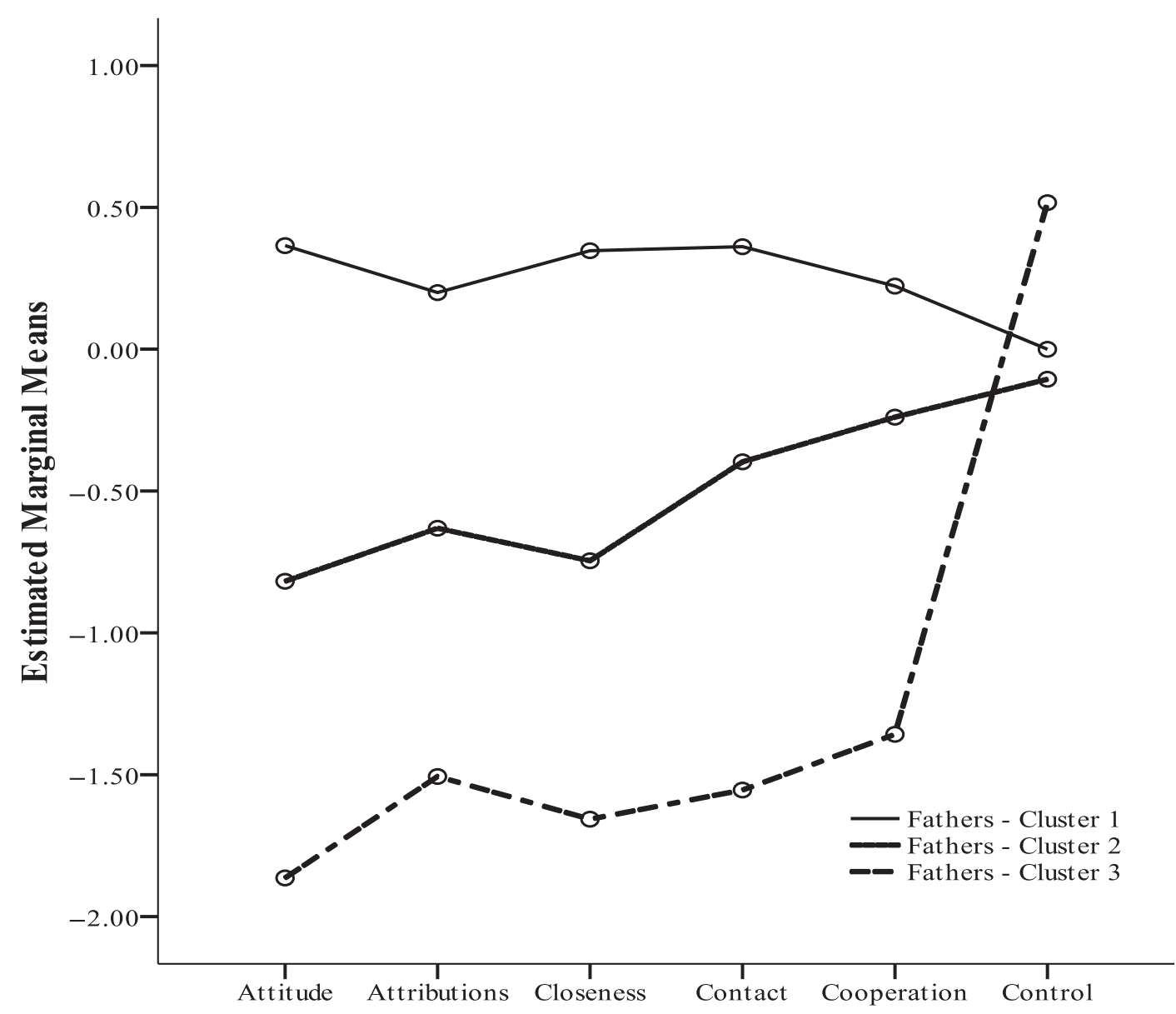

Figure 2. Fathers: Estimated marginal means for each cluster on intrapersonal and interpersonal relationship dimensions

Table 4. Cluster Solutions: Descriptive Statistics and Cluster Differences for Intrapersonal and Interpersonal Dimensions

\begin{tabular}{|c|c|c|c|c|c|c|c|c|c|c|c|c|c|c|}
\hline \multirow[b]{3}{*}{ Relationship dimension } & \multicolumn{7}{|c|}{ Mothers } & \multicolumn{7}{|c|}{ Fathers } \\
\hline & \multicolumn{2}{|c|}{$\begin{array}{l}\text { Cluster I } \\
(n=5 \mathrm{I})\end{array}$} & \multicolumn{2}{|c|}{$\begin{array}{c}\text { Cluster } 2 \\
(n=53)\end{array}$} & \multicolumn{2}{|c|}{$\begin{array}{l}\text { Cluster } 3 \\
(n=25)\end{array}$} & \multirow[b]{2}{*}{$F(2,126)$} & \multicolumn{2}{|c|}{$\begin{array}{l}\text { Cluster I } \\
(n=85)\end{array}$} & \multicolumn{2}{|c|}{$\begin{array}{c}\text { Cluster } 2 \\
(n=4 I)\end{array}$} & \multicolumn{2}{|c|}{$\begin{array}{l}\text { Cluster } 3 \\
(n=19)\end{array}$} & \multirow[b]{2}{*}{$F(2,142)$} \\
\hline & M & $S D$ & $M$ & $S D$ & M & $S D$ & & $M$ & $S D$ & M & $S D$ & $M$ & $S D$ & \\
\hline Attitude & $0.58^{\mathrm{a}}$ & 0.31 & $-0.3 I^{b}$ & 0.39 & $-1.68^{c}$ & 0.97 & $154.17^{* * *}$ & $0.37^{a}$ & 0.47 & $-0.8 I^{b}$ & 0.46 & $-1.86^{c}$ & 0.70 & $186.23 *$ \\
\hline Attribution & $0.16^{a}$ & 0.86 & $-0.04^{\mathrm{a}}$ & 0.94 & $-1.08^{c}$ & 0.84 & $17.02^{* * *}$ & $0.20^{\mathrm{a}}$ & 0.72 & $-0.63^{b}$ & 0.60 & $-\left.1.5\right|^{c}$ & 0.68 & $56.65 * * *$ \\
\hline Closeness & $0.40^{\mathrm{a}}$ & 0.39 & $-0.22^{b}$ & 0.37 & $-1.48^{c}$ & 0.59 & $163.42 * * *$ & $0.35^{\mathrm{a}}$ & 0.43 & $-0.75^{b}$ & 0.40 & $-1.66^{c}$ & 0.62 & $37.19 * * *$ \\
\hline Contact & $0.46^{\mathrm{a}}$ & 0.75 & $-0.33^{c}$ & 0.68 & $-0.70^{c}$ & 0.97 & $23.15 * * *$ & $0.22^{\mathrm{a}}$ & 0.77 & $-0.24^{b}$ & 0.60 & $-1.36^{c}$ & 0.79 & $107.91 * x$ \\
\hline Cooperation & $0.50^{\mathrm{a}}$ & 0.49 & $-0.38^{c}$ & 0.47 & $-0.63^{c}$ & 0.90 & $43.02 * * *$ & $0.36^{a}$ & 0.59 & $-0.40^{b}$ & 0.49 & $-1.55^{c}$ & 0.31 & $192.96 * * *$ \\
\hline Control & 0.00 & 0.81 & 0.15 & 1.18 & -0.01 & 0.87 & 0.39 & -0.00 & 1.02 & -0.11 & 1.07 & 0.52 & 1.09 & 2.43 \\
\hline
\end{tabular}

Note: $N_{\text {mothers }}=129 ; N_{\text {fathers }}=145$. Scores for relationship dimensions are standardized. Means within a row with different superscripts are significantly different.

$* * * * p<.001$.

be described as moderately positive and no greater than Cluster 2. This moderate score may reflect the negative aspects of mothers in this sample. Given that these are mothers with at least some important negative characteristics, the positive scores on attitude, closeness, contact, and cooperation suggest that adult children may minimize or disregard their mother's negative attributes in their overall attitudes and feelings for her and in maintaining a close relationship. Hence, this cluster 
Table 5. Mothers: Hierarchical Regressions of Likelihood of Classification to Mother Clusters Onto Content and Structure of Mother Descriptions

\begin{tabular}{|c|c|c|c|c|c|c|c|c|c|c|c|c|}
\hline \multirow[b]{2}{*}{ Predictor } & \multicolumn{4}{|c|}{ Cluster I } & \multicolumn{4}{|c|}{ Cluster 2} & \multicolumn{4}{|c|}{ Cluster 3} \\
\hline & $\begin{array}{c}\text { Cumulative } \\
R^{2}\end{array}$ & $\begin{array}{l}\text { Increase } \\
\text { in } R^{2}\end{array}$ & $s r^{2}$ & $s r$ & $\begin{array}{c}\text { Cumulative } \\
R^{2}\end{array}$ & $\begin{array}{l}\text { Increase } \\
\text { in } R^{2}\end{array}$ & $s r^{2}$ & $s r$ & $\begin{array}{l}\text { Cumulative } \\
\qquad R^{2}\end{array}$ & $\begin{array}{l}\text { Increase } \\
\text { in } R^{2}\end{array}$ & $s r^{2}$ & $s r$ \\
\hline Step I & .13 & $.13^{* *}$ & & & .05 & .05 & & & .30 & $.30 * * *$ & & \\
\hline $\begin{array}{l}\text { Compartmentalization } \\
\text { (phi) }\end{array}$ & & & .01 & .14 & & & $.03 *$ & $-.18^{*}$ & & & .00 & .04 \\
\hline $\begin{array}{l}\text { Differential } \\
\text { importance (DI) }\end{array}$ & & & .01 & .08 & & & .02 & .15 & & & $.07 * * *$ & $-.27 * * *$ \\
\hline $\begin{array}{l}\text { Proportion of } \\
\text { negatives (neg) }\end{array}$ & & & $.09 * *$ & $-.29 * *$ & & & .01 & .03 & & & $.10 * * *$ & $.31 * * *$ \\
\hline Step 2 & .16 & .03 & & & .12 & $.07 *$ & & & .32 & .02 & & \\
\hline Phi $\times$ Dl & & & $.03 *$ & $.17^{*}$ & & & $.05 * *$ & $.23 * *$ & & & .00 & .06 \\
\hline Phi $\times$ Neg & & & .01 & .11 & & & .01 & .09 & & & .00 & .03 \\
\hline $\mathrm{DI} \times \mathrm{Neg}$ & & & .01 & .07 & & & $.04 *$ & $.19 *$ & & & .02 & .14 \\
\hline Step 3 & .16 & .00 & & & .12 & .00 & & & .32 & .00 & & \\
\hline $\mathrm{Phi} \times \mathrm{DI} \times \mathrm{Neg}$ & & & .00 & .00 & & & .00 & .01 & & & .00 & .01 \\
\hline
\end{tabular}

Note: $N=129 . s r^{2}$ (squared semipartial correlation coefficient) represents the proportion of variance uniquely accounted for by each predictor, beyond what is accounted for by all other predictors at that step. The sign of $s r$ (semipartial correlation coefficient) indicates the direction of the relation between each predictor and the criterion variable.

$*_{p}<.05 . * * p<.01 . * * * p<.001$.

best matches the relationship type previously labeled denying. In comparison to the uniformly positive scores of Cluster 1 across dimensions, Cluster $2(n=53)$ is characterized by moderately positive scores on attitudes, attributions, and closeness, combined with relatively low scores on contact and cooperation. Although these students may not be able to deny their mothers' negative characteristics, they seem to maintain relatively positive attitudes and good closeness, even though (and possibly because) contact and cooperation are low. If contact and cooperation are low because of mothers' perceived negative attributes, then adult children in Cluster 2 may be making the best of a bad situation. We describe this cluster as evaluatively complex because it is similar to Cluster 1 in some respects (attributions) yet similar to Cluster 3 in other respects (contact and cooperation). Cluster 2 best fits the relationship type previously labeled dealing. Cluster $3(n=25)$ was characterized by low scores on all dimensions (except control). Because of their low levels of contact and closeness, these relationships are labeled distancing.

For fathers, the cluster profiles presented in Figure 2 are distinct for all dimensions except control. As shown in Table 4 , on each dimension except control, the scores for Cluster 1 $(n=85)$ are more positive than the scores for Cluster $2(n=41)$, which in turn are more positive than the scores for Cluster 3 $(n=19)$. Thinking in terms of different relationship types, it seems that Cluster 3 are the most troubled relationships and their uniformly poor scores on the relationship dimensions suggest that these fit the distancing type. However, unlike the mother clusters, for which the first two clusters scored similarly on attributions but disparately on contact and cooperation, father clusters show a simpler structure. Clusters 1, 2, and 3 are simply progressively more negative on all dimensions. In other words, they are not evaluatively complex.

\section{Step 3: Linking Parent Structure to Type of Relationship}

Analyses. A hierarchical regression was performed on the likelihood of classification for each of the three relationship clusters to assess the association between relationship types and the organization of parent knowledge displayed in the card sorting task. All predictor variables were centered for the purpose of testing interactions. On Step 1, the main effect terms for evaluative organization (phi), DI, and proportion of negatives (neg) were entered. On Step 2, all two-way interactions of these variables were entered. On Step 3, the threeway interaction of these variables was entered.

Table 5 displays the regression results for mothers. For Cluster 1 (denying), there was a main effect for neg, $\beta=-.35$, $p=.001$, such that participants describing their mothers with relatively few negative attributes had the highest likelihood of classification for Cluster 1 . There was also a significant Phi $\times$ DI interaction, $\beta=.21, p<.05$. Predicted values for this interaction are shown in Figure 3. Positively compartmentalized participants had the highest likelihood of classification to this cluster. For Cluster 2 (dealing), there was a main effect for phi, $\beta=-.22, p<.05$, qualified by a significant Phi $\times$ DI 


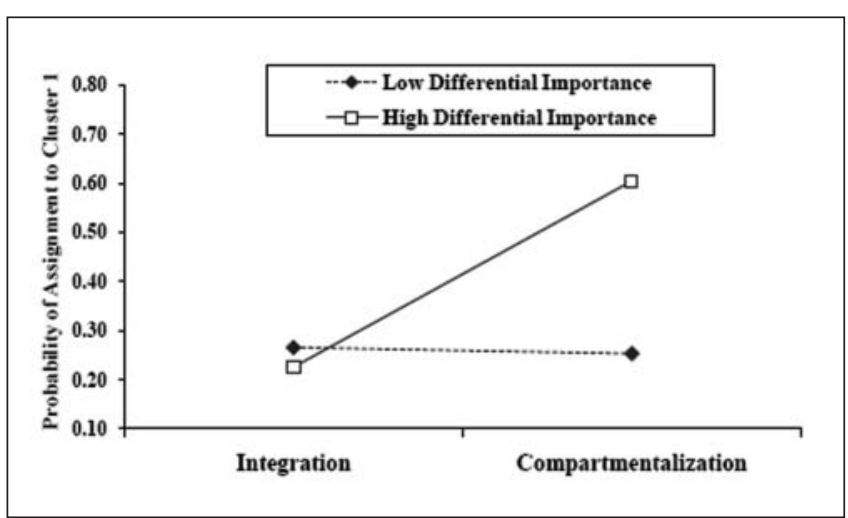

Figure 3. Mothers: Adjusted predicted values for probability of assignment to mother, Cluster I (denying), illustrating the interaction between compartmentalization (phi) and differential importance of mother descriptions at I standard deviation above and below the means

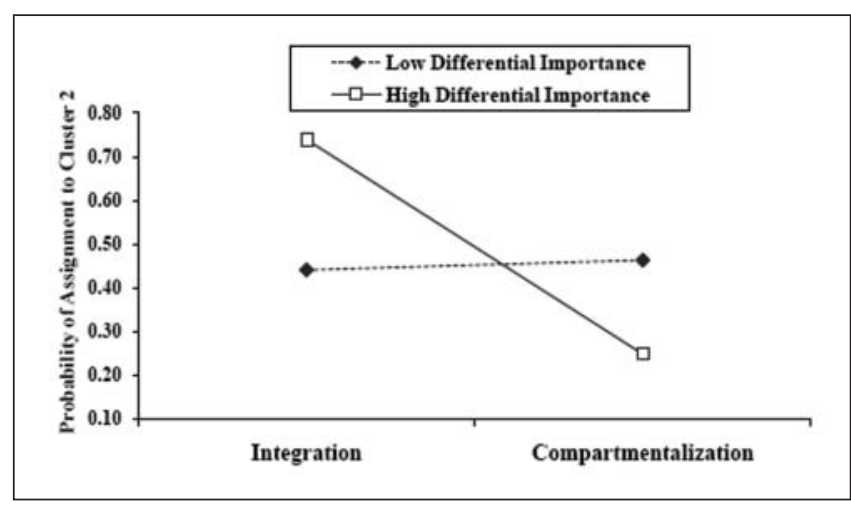

Figure 4. Mothers: Adjusted predicted values for probability of assignment to mother, Cluster 2 (dealing), illustrating the interaction between compartmentalization (phi) and differential importance of mother descriptions at I standard deviation above and below the means

Table 6. Fathers: Hierarchical Regressions of Likelihood of Classification to Father Clusters Onto Content and Structure of Father Descriptions

\begin{tabular}{|c|c|c|c|c|c|c|c|c|c|c|c|c|}
\hline \multirow[b]{2}{*}{ Predictor } & \multicolumn{4}{|c|}{ Cluster I } & \multicolumn{4}{|c|}{ Cluster 2} & \multicolumn{4}{|c|}{ Cluster 3} \\
\hline & $\begin{array}{c}\text { Cumulative } \\
R^{2}\end{array}$ & $\begin{array}{l}\text { Increase } \\
\text { in } R^{2}\end{array}$ & $s r^{2}$ & $s r$ & $\begin{array}{c}\text { Cumulative } \\
R^{2}\end{array}$ & $\begin{array}{l}\text { Increase } \\
\text { in } R^{2}\end{array}$ & $s r^{2}$ & $s r$ & $\begin{array}{c}\text { Cumulative } \\
R^{2}\end{array}$ & $\begin{array}{l}\text { Increase } \\
\text { in } R^{2}\end{array}$ & $s r^{2}$ & $s r$ \\
\hline Step I & .32 & $.32 * * *$ & & & .03 & .03 & & & .34 & $.34 * * *$ & & \\
\hline $\begin{array}{l}\text { Compartmentalization } \\
\text { (phi) }\end{array}$ & & & .00 & .03 & & & .00 & -.01 & & & .00 & -.03 \\
\hline $\begin{array}{l}\text { Differential } \\
\text { importance (DI) }\end{array}$ & & & $.06 * *$ & $.24^{* *}$ & & & .01 & -.08 & & & $.06 * *$ & $-.24 * *$ \\
\hline $\begin{array}{l}\text { Proportion of } \\
\text { negatives (neg) }\end{array}$ & & & $.13 * * *$ & $.36 * * *$ & & & .01 & .11 & & & $.14 * * *$ & $.37 * * *$ \\
\hline Step 2 & .33 & .01 & & & .06 & .03 & & & .44 & $.10 * * *$ & & \\
\hline Phi $\times$ DI & & & .00 & .01 & & & .00 & .05 & & & .01 & .07 \\
\hline Phi $\times$ Neg & & & .00 & .04 & & & .01 & .10 & & & .01 & .07 \\
\hline $\mathrm{DI} \times \mathrm{Neg}$ & & & .01 & .09 & & & .02 & .12 & & & $.08 * * *$ & $.28 * * *$ \\
\hline Step 3 & .34 & .01 & & & .07 & .01 & & & .44 & .00 & & \\
\hline $\mathrm{Phi} \times \mathrm{DI} \times \mathrm{Neg}$ & & & .01 & .09 & & & .01 & .10 & & & .00 & .00 \\
\hline
\end{tabular}

Note: $N=145 . s r^{2}$ (squared semipartial correlation coefficient) represents the proportion of variance uniquely accounted for by each predictor, beyond what is accounted for by all other predictors at that step. The sign of $s r$ (semipartial correlation coefficient) indicates the direction of the relation between each predictor and the criterion variable.

$* * p<.01 . * * * p<.001$.

interaction, $\beta=-.29, p<.01$, as well as a significant $\mathrm{DI} \times \mathrm{Neg}$ interaction, $\beta=.24, p<.05$. The predicted values for the Phi $\times$ DI interaction are shown in Figure 4. Positively integrative participants had the highest likelihood of assignment to this cluster. Predicted values for the DI $\times$ Neg interaction showed that individuals with high DI, but high neg had high likelihood of assignment to this cluster. For Cluster 3 (distancing), there was a main effect of DI, $\beta=-.30, p<.001$, and a main effect for neg, $\beta=.37, p<.001$. Participants who described their mothers with many negative attributes or rated their mother's negative characteristics as more important than their positive ones had the highest likelihood of classification in this cluster.

Table 6 presents the regression results for fathers. These analyses did not show any significant main effects or interactions involving phi, the index of compartmentalization. In other words, assignment to cluster was not affected by evaluative structure, but only by DI and neg, the indices of negativity. For Cluster 1, the most positive cluster, there was a main effect for DI, $\beta=.25, p=.001$ and a main effect for 
Table 7. Descriptive Statistics and Gender Differences for Liking, Loving, and Self-Structure Variables

\begin{tabular}{|c|c|c|c|c|c|c|c|c|c|c|}
\hline \multirow[b]{3}{*}{ Criterion } & \multicolumn{5}{|c|}{ Fathers } & \multicolumn{5}{|c|}{ Mothers } \\
\hline & \multicolumn{2}{|c|}{ Males $(n=40)$} & \multicolumn{2}{|c|}{$\begin{array}{l}\text { Females } \\
(n=105)\end{array}$} & \multirow{2}{*}{$\begin{array}{c}\begin{array}{c}\text { Gender } \\
\text { difference }\end{array} \\
t(143)\end{array}$} & \multicolumn{2}{|c|}{$\begin{array}{c}\text { Males } \\
(n=40)\end{array}$} & \multicolumn{2}{|c|}{$\begin{array}{l}\text { Females } \\
(n=89)\end{array}$} & \multirow{2}{*}{$\begin{array}{c}\begin{array}{c}\text { Gender } \\
\text { difference }\end{array} \\
t(129)\end{array}$} \\
\hline & M & $S D$ & $M$ & $S D$ & & $M$ & $S D$ & M & $S D$ & \\
\hline Liking & 87.85 & 16.15 & 82.87 & 21.84 & $1.50^{\wedge}$ & 86.70 & 16.93 & 88.16 & 18.00 & $-0.43^{\wedge}$ \\
\hline Loving & 65.63 & 15.12 & 60.18 & 19.33 & 1.60 & 69.83 & 14.54 & 72.67 & 16.32 & -0.95 \\
\hline Proportion of negatives & 0.24 & 0.18 & 0.26 & 0.18 & -0.70 & 0.22 & 0.20 & 0.24 & 0.16 & -0.65 \\
\hline Differential importance & 0.19 & 0.61 & 0.15 & 0.66 & 0.35 & 0.26 & 0.59 & 0.46 & 0.49 & $-1.90^{\wedge \wedge}$ \\
\hline Phi & 0.61 & 0.30 & 0.61 & 0.26 & -0.55 & 0.55 & 0.28 & 0.67 & 0.28 & $-2.22^{*}$ \\
\hline
\end{tabular}

$* p<.05 . \wedge^{\wedge} t^{\prime}(94.97) .{ }^{\wedge} t^{\prime}(64.09)$.

neg, $\beta=-.46, p<.001$. There were no significant effects of any predictor variables for Cluster 2 , which fell in between Clusters 1 and 3 on all relationship dimensions except control. For Cluster 3, the most negative cluster, there was a main effect for DI, $\beta=-.25, p=.001$, and a main effect for neg, $\beta=.47, p<.001$. There was also a significant DI $\times$ Neg interaction, $\beta=.36, p<.001$. Predicted values for this interaction confirm that individuals with the most negative perceptions of their fathers (low DI and high neg) are most likely to be assigned to this cluster.

Discussion. Although factor analyses suggested that the same dimensions can be used to characterize adult children's relationships with both mothers and fathers, the cluster analyses identified distinct types of relationships for each parent. Mother-child relationships were evaluatively complex, with the first two clusters showing similarly moderate to negative attributions for the mothers' behaviors yet disparate outcomes in terms of attitude and closeness and especially contact and cooperation. The first cluster, denying, was uniformly positive (except for the moderate attributions). The second cluster, dealing, was moderately positive on attitudes and closeness but relatively low on contact and cooperation. We suggest that in these relationships, physical distance (whether it is created by intention or by chance) may allow adult children to maintain emotional closeness and liking despite perceptions of a parent's flaws. The third cluster, distancing, is uniformly negative on all dimensions and probably represents the most troubled relationships. As predicted, the compartmentalized or integrative structure of parent knowledge predicted the likelihood of assignment to Cluster 1 or Cluster 2. The denying cluster was associated with positive compartmentalization, the dealing cluster was associated with positive integration, and distancing was associated with negative perceptions of the parent, regardless of structure. Thus, for the dealing cluster, evaluatively complex scores on the relationship dimensions are consistent with the evaluatively complex structure of integrative parent knowledge. Denying is consistent with the strategy of compartmentalization, which allows one to sweep negative beliefs under the rug.
In contrast, the relationship clusters for fathers resulted in parallel profiles across relationship dimensions, so that the relationship types directly reflected the negativity of beliefs about fathers. Instead of the hypothesized relationship types, father-child relationships simply varied from not very negative to somewhat negative to very negative. The compartmentalized or integrative structure of father knowledge did not predict assignment to any cluster in this analysis.

\section{Step 4: Moderating Effects of Child Gender}

In this section, we examine whether child gender moderates the parent structure effects described above. Table 7 presents the means and standard deviations by gender of child for the loving, liking, and self-structure variables for fathers and mothers, respectively, for the samples of relatively negative parents included in the cluster analyses. The $t$ tests suggest that females have low liking for their fathers. More importantly for the present study, females are more compartmentalized than males in their representations of their mothers and tend to show higher DI scores. For this reason, the regressions conducted for Step 3 were repeated, including gender of child as a moderator variable.

For mothers, the effects of including gender as a moderator were minimal, and the main conclusions of our previous analyses remain the same. In addition, main effects for gender of child emerged for both the denying and the dealing clusters, such that female adult children had higher likelihood of assignment to the denying cluster, $\beta=.32, p<.001$, whereas male adult children had a higher likelihood of assignment to the dealing cluster, $\beta=-.36, p<.001$. There were no gender effects for the distancing cluster.

Interestingly, for fathers (who were perceived more negatively overall), there were several effects of child gender. For the most positive cluster of father relationships, there was a Phi $\times$ Gender interaction, $\beta=-.14, p=.054$ (when entered stepwise, as the only two-way interaction term), such that integrative female children were most likely to be assigned to this father cluster. For the second cluster, there was a main 
effect for gender, $\beta=-.16, p=.052$, such that male children were most likely to be assigned to this cluster. For the third, most negative cluster, there was a DI $\times$ Gender interaction, $\beta=-.14, p=.051$, such that female children who rated their fathers' negative aspects as highly important were most likely to be assigned to this cluster.

Although these effects must be interpreted with caution because of the low proportion of male children in our sample, it appears that females are more likely to report the most positive type of relationship with either parent. The denying mother-daughter relationship is associated with the daughter's positively compartmentalized view of the mother. The most positive father relationship is reported by integrative daughters. Males were more likely to fit the more reserved Cluster 2 relationships for both parents. Their relatively integrative mother structures explain their tendency to fit the dealing relationship type for mothers.

\section{General Discussion}

\section{Adult Child's Liking and Loving for Parent}

Replicating previous results for the self and romantic partners, evaluatively compartmentalized structures for parent knowledge were associated with relatively extreme positive or negative attitudes, whereas integrative knowledge structures were associated with attitudes that fall between the positive compartmentalized and negative compartmentalized extremes (cf. Showers, 1992; Showers \& Kevlyn, 1999). More specifically, when parent descriptions were relatively positive, compartmentalization was associated with greater liking or loving than was integration of parent attributes. Previous research (Showers, Limke, \& Zeigler-Hill, 2004; Zeigler-Hill \& Showers, 2007) suggests that over the long term, positive compartmentalization may have mixed consequences. Despite the positive attitudes observed in the short term, over the long term ignoring or denying a parent's negative attributes may create inflated or unstable perceptions that are vulnerable to extreme shifts in attitudes when seemingly unimportant negative attributes are suddenly activated.

\section{Parent-Adult Child Relationship Types}

The main goal of this study was to examine whether the types of relationships that college students construct with their parents correspond to evaluatively compartmentalized or integrative knowledge structures for parent knowledge that these adult children display. In other words, we examined whether students who compartmentalized their parents' positive and negative attributes might show a distinct "compartmentalized" type of relationship (e.g., denial of negative attributes or isolation of negative attributes so that they cannot influence closeness or attitudes). Similarly, an integrative parent structure may be associated with an evaluatively complex relationship, for example, one that maintains liking and closeness despite the parent's negative characteristics yet is distant in terms of cooperation and contact (dealing). These hypotheses were confirmed for participants' representations of mother knowledge. The types of mother-child relationships were labeled denying (purely positive on all dimensions, despite acknowledging substantial negative attributes of the mother), dealing (evaluatively mixed, as described above), and distancing (low scores on all relationship dimensions).

In contrast, the types of father-child relationships were not evaluatively complex - the different dimensions of the relationship varied together, forming three relationship clusters that simply varied from highest quality to medium to low. Although a compartmentalized mother structure was associated with the most positive mother-child relationship, for fathers, female adult children with integrative father structures reported the highest quality relationships. These findings may be in part because of the prevalence of females in our participant sample, who may have less complex representations of the opposite- than of the same-sex parent. Moreover, the fact that female children perceive their fathers relatively negatively may mean that compartmentalization is not a successful strategy for managing the father's relatively important negative attributes; instead, integration may be necessary for these women to maintain a positive attitude and relationship with their fathers.

Given this disparity between the types of knowledge structures associated with the most consistently positive relationships with mothers versus fathers, an appropriate direction for future research is to examine the long-term implications of these parent structures and relationship styles. Research on self-structure has shown that, despite the positive mood and high self-esteem associated with positively compartmentalized self-structures, these feelings may be inflated by denial of important negative attributes, such that these individuals are vulnerable to sudden shifts in self-esteem in response to stressful events (Zeigler-Hill \& Showers, 2007). Thus, it would be interesting to test whether positively compartmentalized mother structures are resilient to additional stresses in the relationship (if perhaps the success of compartmentalization is because of less negative attributes from the outset) or whether the most resilient mother relationships are those associated with integration of negative attributes (consistent with the findings for fathers).

Again, in the domain of the self, it is integrative structures that characterize individuals who have experienced the most extreme negative events (Showers, Zeigler-Hill, \& Limke, 2006). One advantage of evaluative integration is that, by keeping negative attributes and beliefs salient along with positive beliefs, it may constitute a realistic outlook in the face of chronic or repeated stressors, whereas compartmentalization may encourage blind optimism.

Another advantage of the integrative parent structure may be that it falls midway on a continuum from enmeshed 
relationships (in which boundaries between parent and child are too weak) to disengaged (in which boundaries are too rigid). In characterizing positive compartmentalized mother structures as denying, we suggest that some of these relationships are enmeshed ones, in which cooperation and contact remain too high, despite the mother's perceived negative attributes, necessitating denial or minimization via compartmentalization.

\section{Limitations}

Restriction of sample to negative parents. It is important to note that the relationship types (clusters) identified here apply only to parents who are perceived as possessing significant negative attributes. Compartmentalized and integrative knowledge structures were originally conceptualized as alternative strategies for how people manage the negative attributes they perceive in themselves or others and, thus, do not apply to people with uniformly positive knowledge structures (should they exist; cf. Showers, 1992; Showers \& Kevlyn, 1999).

Interpersonal control as a dimension of parent-child relationships. One dimension of parent-child relationships that did not vary across relationship clusters and was not associated with the content or structure of parent knowledge was interpersonal control (i.e., the extent to which the adult child felt that he or she could control his or her relationship with his or her parent). This was the only relationship dimension that was not associated with attitude (liking or loving) toward the parent. Instead, greater interpersonal control by the child was correlated with both less conflict and less cooperation, even though the latter is usually perceived as a sign of low relationship quality. Thus, this variable seems to play dual roles that should be disentangled in future research.

Direction of causality. The compartmentalization model suggests that knowledge structures may influence relationship outcomes. For example, compartmentalization may reduce accessibility of parents' negative traits, allowing relationships to proceed as if the negative attributes did not exist. However, it is important to note that the direction of causality may also be reversed. These knowledge structures may reflect established relationship styles. That is, adult children who have little contact with parents for purely logistical reasons may be prone to develop integrative parent structures, if distance allows rumination about salient negative attributes. Adult children who see parents frequently may tend to compartmentalize their negative traits to maintain working knowledge structures that are easy and efficient.

Regardless of causal direction, the link between underlying knowledge structures and relationship types suggests that by changing these structures it may be possible to negotiate more positive or negative relationships. For example, adult children who are continually focused on both positive and negative beliefs about their parents might benefit by learning to isolate their negative beliefs about their parents to specific contexts (e.g., "she is only irresponsible when she is with her friends") and avoiding these specific situations or by construing their parent aspects to exclude those specific beliefs (cf. Mahoney, 1974). In contrast, compartmentalized individuals who are constantly aware of their parents' negative characteristics might benefit from developing "yes, but" attitudes (e.g., "yes, she is irresponsible, but she is also lighthearted and energetic") that may cushion the impact of these negative characteristics (cf. Murray \& Holmes, 1999).

\section{Conclusions}

Consistent with previous work on romantic relationships, college students' structure of parent knowledge predicted feelings of liking and loving for parents. In addition, structure of parent knowledge was associated with distinct parentadult child relationship types. Positively compartmentalized mother structures were associated with denying relationships in which mothers' negative attributes were denied, excused, or ignored. In contrast, positively integrative mother structures were associated with evaluatively complex dealing relationships that were low on contact and cooperation but moderately close. Father-child relationships varied more simply along a single evaluative dimension, with the most positive relationships reported by daughters with integrative representations of their fathers. These findings extend previous work that links the organization of knowledge about romantic partners to relationship outcomes, suggesting that cognitive structures for beliefs about another may either alter or reflect the nature of that relationship. This work also provides a template for understanding parent-adult child relationship types.

\section{Acknowledgments}

These data were collected in partial fulfillment of the requirements for Alicia Limke's dissertation project.

\section{Declaration of Conflicting Interests}

The authors declared no potential conflicts of interests with respect to the authorship and/or publication of this article.

\section{Financial Disclosure/Funding}

The authors received no financial support for the research and/or authorship of this article.

\section{Note}

1. The additional 20 traits were obtained from a pilot study in which participants generated aspects and attributes to describe parents. Attributes generated that were not already represented conceptually in the card sort deck were added. To confirm the valence of these attributes, 15 independent judges rated them as positive or negative. The interrater agreement was $98.7 \%$ across all 20 items. 


\section{References}

Agnew, C. R., Van Lange, P. A. M., Rusbult, C. E., \& Langston, C. A. (1998). Cognitive interdependence: Commitment and the mental representation of close relationships. Journal of Personality and Social Psychology, 74, 939-954.

Andersen, S. M., \& Cole, S. W. (1990). "Do I know you?”: The role of significant others in general social perception. Journal of Personality and Social Psychology, 59, 384-399.

Aquilino, W. S. (1997). From adolescent to young adult: A prospectus study of parent-child relations during the transition to adulthood. Journal of Marriage and Family, 59, 670-686.

Aron, A., Aron, E. N., \& Smollan, D. (1992). Inclusion of Other in the Self Scale and the structure of interpersonal closeness. Journal of Personality and Social Psychology, 63, 596-612.

Baldwin, M. W. (1992). Relational schemas and the processing of information. Psychological Bulletin, 112, 461-484.

Belsky, J., Jaffee, S. R., Hsieh, K., \& Silva, P. A. (2001). Childrearing antecedents of intergenerational relations in young adulthood: A prospective study. Developmental Psychology, 37, 801-813.

Berscheid, E., Snyder, M., \& Omoto, A. M. (1989). The Relationship Closeness Inventory: Assessing the closeness of interpersonal relationships. Journal of Personality and Social Psychology, 57, 792-807.

Bowlby, J. (1969). Attachment and loss: Vol. 1. Attachment. New York, NY: Basic Books.

Cicirelli, V. G. (1995). A measure of caregiving daughters' attachment to elderly mothers. Journal of Family Psychology, 9, 89-94.

Cook, W. L. (1993). Interdependence and the interpersonal sense of control: An analysis of family relationships. Journal of Personality and Social Psychology, 64, 587-601.

Cramer, H. (1946). Mathematical methods of statistics. Princeton, NJ: Princeton University Press. (Original work published 1945)

Fincham, F. D., Beach, S. R. H., Arias, I., \& Brody, G. H. (1998). Children's attributions in the family: The Children's Relationship Attribution Measure. Journal of Family Psychology, 12, 481-493.

Fincham, F. D., \& Bradbury, T. N. (1992). Assessing attributions in marriage: The Relationship Attribution Measure. Journal of Personality and Social Psychology, 62, 457-468.

Frank, S. J., Avery, C. B., \& Laman, M. S. (1988). Young adults' perceptions of their relationships with their parents: Individual differences in connectedness, competence, and emotional autonomy. Developmental Psychology, 24, 729-737.

Greene, A. L., \& Boxer, A. M. (1986). Daughters and sons as young adults: Restructuring the ties that bind. In N. Datan, A. L. Greene, \& H. W. Reese (Eds.), Life-span developmental psychology: Intergenerational relations (pp. 125-149). Hillsdale, NJ: Lawrence Erlbaum.

Holmes, J. G., \& Boon, S. D. (1990). Developments in the field of close relationships: Creating foundations for intervention strategies. Personality and Social Psychology Bulletin, 16, 23-41.
Jacobvitz, D. B., \& Bush, N. F. (1996). Reconstructions of family relationships: Parent-child alliances, personal distress, and selfesteem. Developmental Psychology, 32, 732-743.

Johnson, D. J., \& Rusbult, C. E. (1989). Resisting temptation: Devaluation of alternative partners as a means of maintaining commitment in close relationships. Journal of Personality and Social Psychology, 57, 967-980.

Linville, P. W. (1987). Self-complexity as a cognitive buffer against stress-related illness and depression. Journal of Personality and Social Psychology, 52, 663-676.

Mackensen, G., \& Cottone, R. R. (1992). Family structural issues and chemical dependency: A review of the literature from 1985 to 1991. American Journal of Family Therapy, 20, 227-241.

Mahler, M. (1975). The psychological birth of the human infant. New York, NY: Basic Books.

Mahoney, M. J. (1974). Self-reward and self-monitoring techniques for weight control. Behavior Therapy, 5, 48-57.

McLachlan, G., \& Krishnan, T. (1997). The EM algorithm and extensions. New York, NY: John Wiley.

Miller, R. S., \& Lefcourt, H. M. (1982). The assessment of social intimacy. Journal of Personality Assessment, 46, 514-518.

Murray, S. L., \& Holmes, J. G. (1993). Seeing virtues in faults: Negativity and the transformation of interpersonal narratives in close relationships. Journal of Personality and Social Psychology, 65, 707-722.

Murray, S. L., \& Holmes, J. G. (1999). The (mental) ties that bind: Cognitive structures that predict relationship resilience. Journal of Personality and Social Psychology, 77, 1228-1244.

Neff, L. A., \& Karney, B. R. (2004). How does context affect intimate relationships? Linking external stress and cognitive processes within marriage. Personality and Social Psychology Bulletin, 30, 134-148.

Pelham, B. W., \& Swann, W. B., Jr. (1989). From self-conceptions to self-worth: On the sources and structure of global self-esteem. Journal of Personality and Social Psychology, 57, 672-680.

Pierce, G. R., Sarason, I. G., \& Sarason, B. R. (1991). General and relationship-based perceptions of social support: Are two constructs better than one? Journal of Personality and Social Psychology, 61, 1028-1039.

Riggio, H. R. (2004). Parental marital conflict and divorce, parentchild relationships, social support, and relationship anxiety in young adulthood. Personal Relationships, 11, 99-114.

Rubin, Z. (1970). Measurement of romantic love. Journal of Personality and Social Psychology, 16, 265-273.

Showers, C. (1992). Compartmentalization of positive and negative self-knowledge: Keeping bad apples out of the bunch. Journal of Personality and Social Psychology, 62, 1036-1049.

Showers, C. J., Abramson, L. Y., \& Hogan, M. E. (1998). The dynamic self: How the content and structure of the self-concept change with mood. Journal of Personality and Social Psychology, 75, 478-493.

Showers, C. J., \& Kevlyn, S. B. (1999). Organization of knowledge about a relationship partner: Implications for liking and loving. Journal of Personality and Social Psychology, 76, 958-971. 
Showers, C. J., \& Kling, K. C. (1996). Organization of selfknowledge: Implications for recovery from sad mood. Journal of Personality and Social Psychology, 70, 578-590.

Showers, C. J., Limke, A., \& Zeigler-Hill, V. (2004). Self-structure and self-change: Applications to psychological treatment. Behavior Therapy, 35, 167-184.

Showers, C. J., \& Zeigler-Hill, V. (2004). Organization of partner knowledge: Relationship outcomes and longitudinal change. Personality and Social Psychology Bulletin, 30, 1198-1207.

Vangelisti, A. L., \& Young, S. L. (2000). When words hurt: The effects of perceived intentionality on interpersonal relationships. Journal of Social and Personal Relationships, 17, 393-424.
Watt, T. T. (2002). Marital and cohabitating relationships of adult children of alcoholics: Evidence from the National Survey of Families and Households. Journal of Family Issues, 23, 246-265.

Zajonc, R. B. (1960). The process of cognitive tuning in communication. Journal of Abnormal and Social Psychology, 61, 159-167.

Zeigler-Hill, V., \& Showers, C. J. (2007). Self-structure and selfesteem stability: The hidden vulnerability of compartmentalization. Personality and Social Psychology Bulletin, 33, 143-159. 